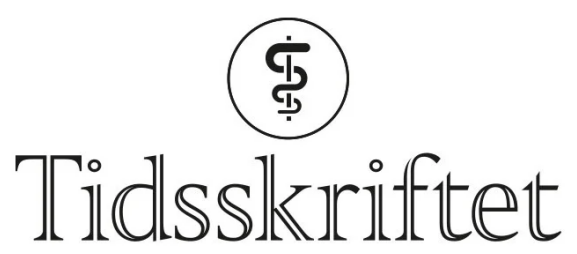

DEN NORSKE LEGEFORENING

\title{
Intern herniering gjennom Winslows foramen
}

\author{
KORT KASUISTIKK
}

\section{SAIRA MAULAND MANSOOR}

saira.m.mansoor@gmail.com

Kirurgisk avdeling

Vestre Viken, Bærum sykehus

Saira Mauland Mansoor er lege i spesialisering i generell og gastroenterologisk kirurgi.

Forfatteren har fylt ut ICMJE-skjemaet og oppgir ingen interessekonflikter.

\section{OLE JACOB GRANDAHL}

Radiologisk avdeling

Vestre Viken, Bærum sykehus

Ole Jacob Grandahl er spesialist i radiologi og overlege.

Forfatteren har fylt ut ICMJE-skjemaet og oppgir ingen interessekonflikter.

\section{TORUNN FETVEIT}

Kirurgisk avdeling

Vestre Viken, Bærum sykehus

Torunn Fetveit er spesialist i gastroenterologisk kirurgi og seksjonsoverlege.

Forfatteren har fylt ut ICMJE-skjemaet og oppgir ingen interessekonflikter.

\section{Intern herniering gjennom Winslows foramen (foramen epiploicum) er en sjelden årsak til tarmslyng. Denne kasuistikken omhandler en pasient som ble innlagt på sykehus på grunn av oppkast og epigastriesmerter forårsaket av tilstanden.}

En kvinne i 8o-årene som hadde hatt hjerteinfarkt åtte år tidligere, ble innlagt via akuttmottak grunnet akutte smerter i epigastriet samt kvalme og oppkast. Det ble gitt nitroglyserin sublingvalt i ambulansen, med forbigående smertelindring. I akuttmottaket var pasienten tydelig smertepåvirket, og hun hadde liten effekt av morfin intravenøst. Hun kastet opp flere ganger, og metoklopramid (Afipran) intravenøst hadde liten eller ingen kvalmestillende effekt. Pasienten hadde hatt avføring siste dag før innleggelsen. Hun var svært palpasjonsøm i hele buken, mest uttalt i epigastriet, og det var sparsomt med tarmlyder. Vitale målinger var uten anmerkning. EKG var uten tegn til akutt iskemi. Blodprøver viste følgende verdier: CRP $4 \mathrm{mg} / \mathrm{L}$ ( referanseområde $<5$ ), leukocytter 9,7 × 109/L 
(3,5-10,0 $\left.\times 10^{9}\right)$, natrium $141 \mathrm{mmol} / \mathrm{L}(137-145)$, kalium 4,7 mmol/L (3,6-5,o), kreatinin 53 $\mu \mathrm{mol} / \mathrm{L}(45-90)$, troponin $13 \mathrm{ng} / \mathrm{L}(<14)$. Lever- og galleprøver var også normale. Arteriell blodgassanalyse viste laktat på $2,5 \mathrm{mmol} / \mathrm{L}(<1,6)$.

Etter å ha utelukket kardial årsak til pasientens magesmerter, på grunnlag av normalt EKG og normal troponinverdi, ble det bedt om tilsyn fra vakthavende gastrokirurg. På bakgrunn av sykehistorien med oppkast og magesmerter som ikke lot seg lindre av morfin, samt forhøyet laktatverdi, ble det med tanke på akutte, behandlingskrevende differensialdiagnoser som tarmslyng og tarmiskemi anbefalt snarlig CT abdomen.

CT abdomen ble utført på innleggelsesdagen og viste oppslått og dilatert cøkum i epigastriet, bak en sammenfalt ventrikkel og minimalt utspilt tynntarm. Dette ble av vakthavende radiolog først tolket som cøkum-volvulus, men endelig beskrivelse i samråd med kontrasignerende radiolog presiserte at det dreide seg om en intern herniering av cøkum gjennom Winslows foramen (figur 1).

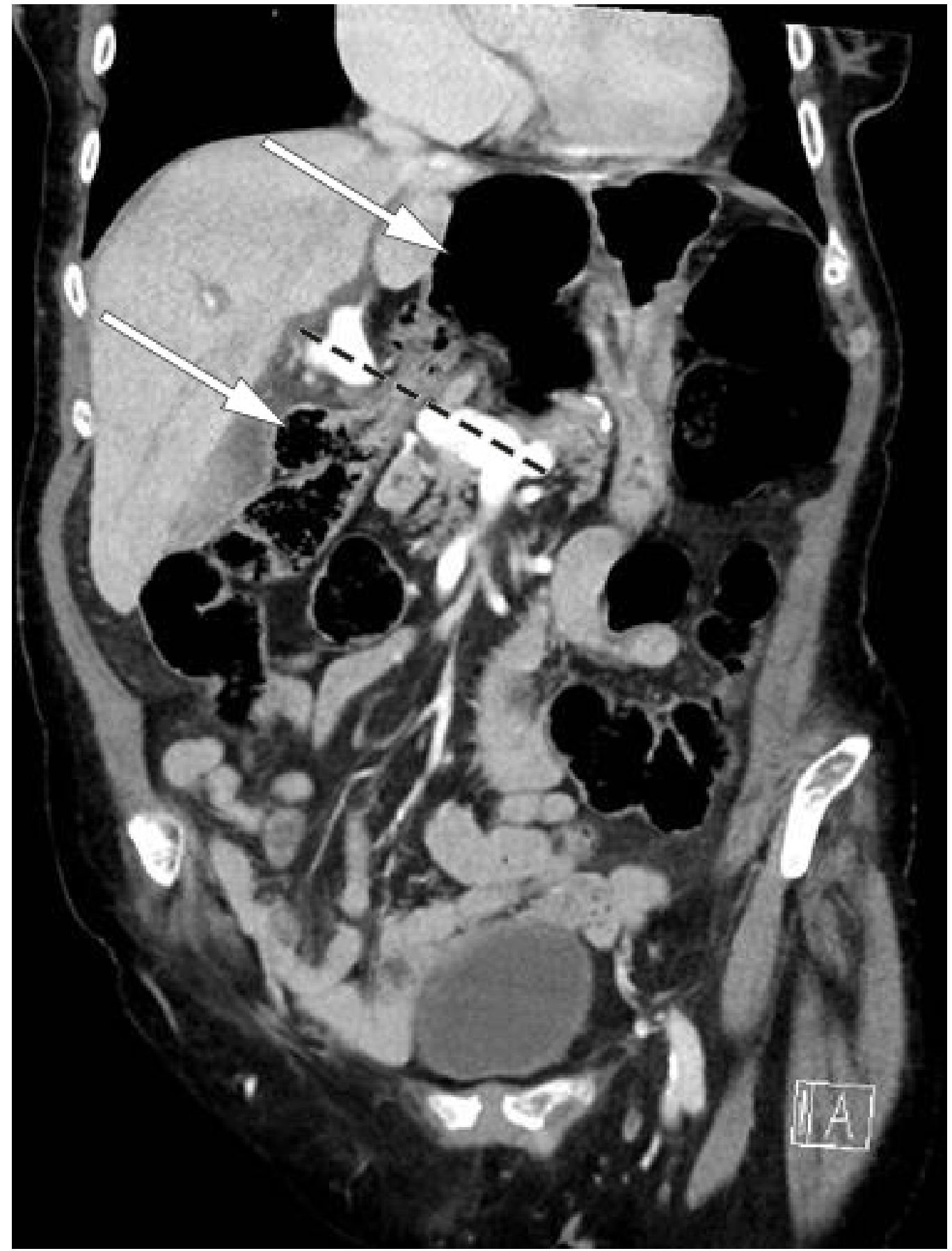

Figur 1 CT av buken, aksialplan. Pilene peker på cøkum som er herniert gjennom Winslows foramen og ligger som en luftfylt tarmslyng i epigastriet. Den stiplede linjen markerer 
ligamentum hepatoduodenale, hvor det er vena portae som er kontrastladende på dette bildet. Tynntarmen er dilatert, og ventrikkelen er sammenfalt.

Pasienten hadde altså en spontan og sjelden form for intern herniering som forårsaket tarmslyng. På bakgrunn av kliniske undersøkelser og CT-funn ble det funnet indikasjon for operativ behandling. Pasienten ønsket i første omgang ikke kirurgi. Hun ble lagt på kirurgisk sengepost med ventrikkelsonde og intravenøs væsketilførsel samt smertelindring med morfin, med varierende effekt. På dette tidspunkt var hun mindre utspilt i buken og ikke lenger palpasjonsøm i epigastriet. Dermed var det ikke mistanke om truet tarm, og det ble ansett som trygt å observere pasienten videre. Ved kontroll av blodprøver var CRP fortsatt $4 \mathrm{mg} / \mathrm{L}$, leukocytter steget til 14,7 $\times 10^{9} / \mathrm{L}$ og venøs laktat 4 $\mathrm{mmol} / \mathrm{L}(<2,5)$. Ett døgn etter innleggelsen samtykket pasienten til kirurgi, etter gjentatte samtaler med kirurg. Hun ble operert morgenen etter med laparoskopisk reponering av cøkum (figur 2). Dette lot seg uproblematisk gjøre ved lett traksjon, med samtidig kompresjon av den luftfylte cøkum. Tarmen var viabel.

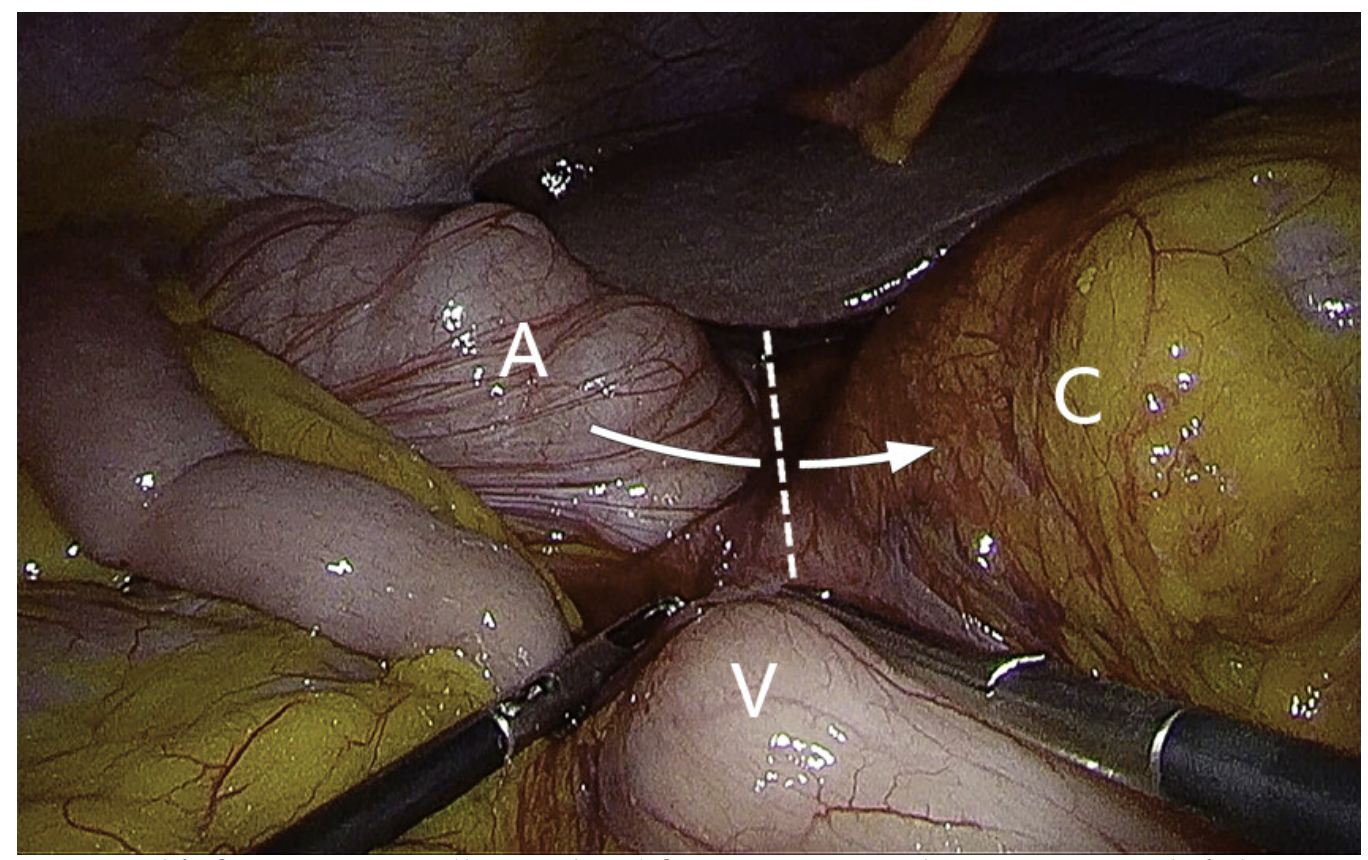

Figur 2 Bilde fra operasjonen (laparoskopi) før reponering av herniet. Den stiplede linjen markerer ligamentum hepatoduodenale, og pilen markerer hernieringen gjennom Winslows foramen. $A=$ colon ascendens, $C=c ø k u m$, som ligger luftfylt bak omentum minus, $\mathrm{V}=$ ventrikkel.

Det postoperative forløpet var ukomplisert. Pasienten ville reise hjem dagen etter operasjonen, tross anbefaling om ytterligere observasjon på sykehus. Ønsket ble innfridd i samråd med pårørende. Ved utskrivelse hadde pasienten kommet i gang med matinntak, hun hadde ingen smerter eller kvalme, men hadde ikke hatt luftavgang eller avføring. Arteriell blodgassanalyse viste normalisering av laktat til o,9 mmol/L, natrium $140 \mathrm{mmol} / \mathrm{L}$ og kalium 3,4 mmol/L. Ved telefonisk kontakt etter én måned var pasienten fullstendig restituert og hadde ingen tegn til residiv.

\section{Diskusjon}

Winslows foramen (også kjent som foramen epiploicum) er åpningen som leder til det naturlige hulrommet bursa omentalis, bak omentum minus. Denne åpningen passerer foran vena cava inferior og bak ligamentum hepatoduodenale, som består av ductus choledochus, vena portae og arteria hepatica propria. Normalt er Winslows foramen lukket, som et resultat av det lave intraabdominale trykket. I litteraturen er det er foreslått tre risikofaktorer for herniering her: 1 ) økt mobilitet av intraabdominale organer, som følge av for eksempel langt tarmkrøs eller manglende tilhefting av høyre kolon, 2) unormalt forstørret foramen og 3 ) endringer i intraabdominalt trykk (1). 
Intern herniering gjennom Winslows foramen er meget sjelden, med kun 150-20o tilfeller beskrevet i litteraturen $(\mathbf{1}, \underline{2})$. I to tredeler av tilfellene er det tynntarm som hernierer, dernest cøkum og colon ascendens $(\underline{1}, 3)$. Tilstanden har høy morbiditet og mortalitet $(\underline{1})$. Symptomene relaterer seg ofte til oppstått tarmslyng, men ikterus kan også oppstå som følge av kompresjon av eksterne galleveier $(4,5)$.

Diagnosen stilles ofte ved hjelp av en CT-undersøkelse der de typiske funnene er endret lokalisasjon av colon ascendens, bløtvev mellom vena cava og vena portae, og luft eller væske i bursa omentalis $(\underline{6}, 7$. .). Som for tarmslyng generelt vil behandlingen ofte være operasjon, enten ved laparotomi eller laparoskopi. Hvis man ikke lykkes med å reponere tarmen, kan Winslows foramen utvides ved kocherisering (løsning av duodenum) eller ved å åpne omentum minus (1). Det er også beskrevet deflatering av tarm med

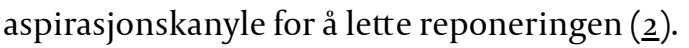

Det foreligger ikke retningslinjer som gjelder tiltak for å forhindre tilbakefall, da det mangler oppfølgingsstudier $(\underline{1}, 5, \underline{8})$. Ulike tilnærminger er foreslått: lukking av foramen, fiksering av høyre kolon eller cøkum, eller høyresidig hemikolektomi $(\underline{1}, \underline{2}, \underline{8})$. En oversiktsartikkel fra 2019 presenterer 15 kasuistikker der tilstanden ble behandlet laparoskopisk (1). I fire tilfeller ble foramen lukket, i to tilfeller ble cøkum fiksert, og i de resterende ble ingen preventive tiltak foretatt. Ingen av pasientene fikk residiv, men observasjonstiden oversteg ikke 21 måneder (1). I kasuistikker der foramen ble lukket, er det beskrevet lukking med oment eller direkte suturering (므). Ved suturlukking blir peritoneum omkring ligamentum hepatoduodenale festet til bakre bukvegg $(\underline{8}, 9)$.). Faren her vil naturlig nok være å skade hovedgallegangen eller blodforsyningen til leveren (5).

I denne kasuistikken hadde pasienten et heldig forløp av en mulig livstruende tilstand. Ut ifra det kliniske bildet og liten dilatasjon av tynntarm kan det tenkes at det ikke forelå et fullstendig passasjehinder. Årsaken hos denne pasienten var sannsynligvis en kombinasjon av lav kroppsvekt (lite intraabdominalt fett) og en mobil cøkum. Winslows foramen var ikke unormalt forstørret. Det forelå ingen kjente faktorer som gav økt intraabdominalt trykk, men obstipasjonsplager hos pasienten ble ikke kartlagt. Det ble ikke utført residivforebyggende tiltak under operasjonen, da dette syntes risikabelt og uten evidens (1, 5, ). Etter seks måneders observasjonstid har pasientjournalen ikke vist residiv.

Pasienten har gitt samtykke til at artikkelen blir publisert.

Artikkelen er fagfellevurdert.

\section{REFERENCES}

1. Moris D, Tsilimigras DI, Yerokun B et al. Foramen of Winslow Hernia: a Review of the Literature Highlighting the Role of Laparoscopy. J Gastrointest Surg 2019; 23: 2093-9. [PubMed][CrossRef]

2. Harnsberger CR, McLemore EC, Broderick RC et al. Foramen of Winslow hernia: a minimally invasive approach. Surg Endosc 2015; 29: 2385-8. [PubMed][CrossRef]

3. Puig CA, Lillegard JB, Fisher JE et al. Hernia of cecum and ascending colon through the foramen of Winslow. Int J Surg Case Rep 2013; 4: 879-81. [PubMed][CrossRef]

4. Joo YE, Kim HS, Choi SK et al. Internal hernia presenting as obstructive jaundice and acute pancreatitis. Scand J Gastroenterol 2002; 37: 983-6. [PubMed][CrossRef]

5. Tjandra JJ, Collier N. Obstructive jaundice due to foramen of Winslow hernia: a case report. Aust N Z J Surg 1991; 61: 467-9. [PubMed][CrossRef]

6. Costa GD, Ng B, Kociumbas I et al. Herniation of caecum through the foramen of Winslow. Australas Radiol 2007; 51: B152-4. [PubMed][CrossRef]

7. Wojtasek DA, Codner MA, Nowak EJ. CT diagnosis of cecal herniation through the foramen of Winslow. Gastrointest Radiol 1991; 16: 77-9. [PubMed][CrossRef]

8. Ayoob F, Michael R, Chadnick Z et al. Internal hernia of caecum through the foramen of Winslow. BMJ Case Rep 2019; 12: e228239. [PubMed][CrossRef] 
9. Garg S, Flumeri-Perez G, Perveen S et al. Laparoscopic Repair of Foramen of Winslow Hernia. Int J Angiol 2016; 25: 64-7. [PubMed]

Publisert: 31. januar 2022. Tidsskr Nor Legeforen. DOI: 10.4045/tidsskr.21.0326

Mottatt 18.4.2021, første revisjon innsendt 31.7.2021, godkjent 27.9.2021.

Publisert under åpen tilgang CC BY-ND. Lastet ned fra tidsskriftet.no 26. april 2023. 